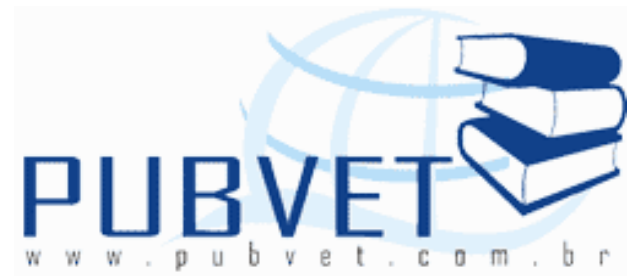

PUBVET, Publicações em Medicina Veterinária e Zootecnia.

\title{
Relação sexual do parasitismo por Haemonchus contortus em Caprinos (Capra hircus)
}

\section{Zuliete Aliona Araújo de Souza Fonseca ${ }^{1 *}$, Adiza Cristiane Avelino} Bezerra ${ }^{1}$, Danielly Bezerra Avelino ${ }^{1}$, Janilene de Oliveira nascimento ${ }^{2}$, Ana Sabrina Coutinho Marques ${ }^{2}$, Luiz da Silva Vieira ${ }^{3}$, Silvia Maria Mendes Ahid $^{4}$

${ }^{1}$ Discente de Pós Graduação em Ciência Animal da Universidade Federal Rural do Semi-Árido (UFERSA).

*Autor para correspondência: E-mail: alionahta@hotmail.com

${ }^{2}$ Discente de graduação em Medicina Veterinária da UFERSA

${ }^{3}$ Pesquisador da Embrapa Caprinos e Ovinos. e-mail

${ }^{4}$ Docente do Departamento de Ciências Animais, coordenadora do laboratório de Parasitologia da Universidade Federal Rural do Semi-Árido (UFERSA).

\section{Resumo}

A hemoncose é uma doença parasitaria importante para pecuária, sendo os ovinos e caprinos as espécies que apresentam um maior acometimento. Esta enfermidade é provocada pelo nematódeo de gênero Haemonchus sp., parasito de abomaso, medindo entre 1 a 2,5 cm. Tratase da mais patogênica das helmintoses, provocando diminuição do ganho de peso, graves anemias, edemas de mucosa gástrica diminuindo a 
FONSECA, Z.A.A.S. et al. Relação sexual do parasitismo por Haemonchus contortus em Caprinos (Capra hircus). PUBVET, Londrina, V. 5, N. 31, Ed. 178, Art. 1200, 2011.

absorção de nutrientes, edemas externos denominados "edema de barbela", sendo sua sintomatologia característica de hemoncose, além de

provocar óbito em graves parasitoses. O objetivo deste trabalho foi descrever a fauna parasitária abomasal e a relação sexual do parasitismo por Haemonchus contortus. Foram coletadas amostras abomasais de caprinos após o abate, sendo recuperado um total de 12460 helmintos. Os animais abatidos foram observados no pré abate e pós abate. No pré abate foram observados pelos arrepiados e sem brilho além de anemias grave. Após o abate foi observado o parasitismo abomasal por $H$. contortus e $T$. axei, onde a carga parasitária do $H$. contortus representou mais de $98 \%$ do parasitismo, sendo a relação entre macho e fêmea equivalente, além do parasitismo observou-se lesões de mucosa provocado pela fixação do nematóide ao órgão e carcaça pálida.

Palavras chaves: anemia, edema, haemonchus contortus, helmintose, parasitose

\title{
Sexual relationship of parasitism by Haemonchus contortus in Goats (Capra hircus)
}

\begin{abstract}
The hemoncose is an important parasitic disease to livestock, being the species sheep and goats the most affected. This disorder is caused by the nematode Haemonchus sp. abomasal parasite, measuring 1 to $2.5 \mathrm{~cm}$. This is the most pathogenic helminthes, causing reduction of weight gain, severe anemia, edema of the gastric mucosa promoting decreasing the absorption of nutrients, external swelling called "edema of dewlap", and it's characteristic signs of hemoncose, besides causing death in severe parasitosis. The aim of this study was describe the abomasal parasite fauna and sexual parasitism with Haemonchus contortus. Abomasal samples were collected after slaughter of goats, being recovered a total of 12460 helminths. The slaughtered animals were observed before and
\end{abstract}


FONSECA, Z.A.A.S. et al. Relação sexual do parasitismo por Haemonchus contortus em Caprinos (Capra hircus). PUBVET, Londrina, V. 5, N. 31, Ed. 178, Art. 1200, 2011.

after slaughter. Before the slaughter were observed hair bristly and opaque, beyond severe anemia. After killing was observed abomasal parasitism by $H$. contortus and $T$. axei, where the parasitic load of $H$. contortus was accounted for more than $98 \%$ of parasitism, being equivalent the relation between male and female, in addition of the parasitism was observed mucosal lesions caused by fixation of nematode in abomasum, and pale carcass .

Keywords: Anemia, edema, haemonchus contortus, helminthes, parasitosis.

\section{INTRODUÇÃO}

No Brasil, o efetivo caprino é de cerca de 10 milhões de cabeças, com uma evolução de $43,8 \%$ do efetivo e taxas de crescimento de $43,3 \%$ para o Nordeste, e de $100 \%$ para o estado do Rio Grande do Norte. Na região semi árida, o maior entrave são as práticas de manejo inadequadas, especialmente sanitárias, o que interfere na produção do rebanho, mesmo porque as condições climáticas favorecem a ação de varias espécies de endoparasitos simultâneos, acentuando os danos causados pelos vermes gastrintestinais nos animais criados a campo (SANTOS et al., 2006).

Os nematódeos de maior importância para os pequenos ruminantes são: Haemonchus contortus, Trichostrongylus colubriformis, Strongyloides spp., Cooperia curticei e Oesophagostomum columbianum de ocorrência mais frequente na região Sudeste e Nordeste. O principal helminto considerado problema nas criações é o $H$. contortus por ser hematófago, perfuram os vasos sanguíneos da parede do abomaso consumindo entre 0,05 a 0,08mL de sangue/dia (QUADROS et al., 2004). Portanto um animal parasitado com $4.000 \mathrm{H}$. contortus pode estar perdendo diariamente $200 \mathrm{ml}$ de sangue, segundo Pinheiro, (1983). 
FONSECA, Z.A.A.S. et al. Relação sexual do parasitismo por Haemonchus contortus em Caprinos (Capra hircus). PUBVET, Londrina, V. 5, N. 31, Ed. 178, Art. 1200, 2011.

Apesar das infecções serem mistas, $H$. contortus apresentam maior prevalência e intensidade de infecção. Animais infectados por esse nematóide, na fase aguda da parasitose, apresentam perda de peso, desidratação, diarréia, anemia e pelos arrepiados e sem brilho. Em altas infecções, ainda na fase aguda, a anemia poderá ser intensa, quando facilmente se nota a mucosa ocular, gengival e vulvar extremamente pálida, podendo haver morte já nessa fase, o que caracteriza uma infecção hiperaguda. Na fase crônica, esses sinais intensificam-se, podendo ser observado edemas na região submandibular e ventral, em virtude da hiperalbuminemia (FREITAS, 1982; SANTA ROSA, 1996 apud CAVALCANTE et al., 2009).

O parasitismo por $H$. contortus apresenta elevada patogenia provocado pelo hematofagismo, sendo agravado pelas condições climáticas e alto poder de contaminação das pastagens provocado pela grande quantidade de ovos eliminados pelas fêmeas deste parasito, que pode produzir de 5.000 a 10.000 ovos por dia, aumentando a ovipostura consideravelmente quando as fêmeas parasitadas entram no período de parto e lactação, provocada pelo desenvolvimento das larvas em hipobiose (CARVALHO et al., 2001). Desse modo o objetivo do presente trabalho foi de relatar a relação sexual e carga parasitária de $H$. contortus em caprinos jovens abatidos e destinados ao consumo humano.

\section{MATERIAL E MÉTODOS}

Foram coletadas amostras abomasais de caprinos jovens destinados ao abate, onde os mesmos foram observados no pré-abate e pós-abate. Para recuperação dos helmintos, a mucosa do abomaso e seu conteúdo foi lavado e filtrados em tamises, sendo a mucosa cuidadosamente vistoriada para remoção de exemplares aderidos. Todo o conteúdo recuperado da lavagem dos órgãos foram submetidos a análise e identificação,onde os 
FONSECA, Z.A.A.S. et al. Relação sexual do parasitismo por Haemonchus contortus em Caprinos (Capra hircus). PUBVET, Londrina, V. 5, N. 31, Ed. 178, Art. 1200, 2011.

espécimes recuperados foram fixados e mantidos no AFA (Álcool, Formol e Ácido acético), posteriormente conservados em Álcool a 70\% glicerinado a $10 \%$ até a identificação e contagem, segundo bibliografia especializada.

A análise estatística utilizada nesse estudo foi meramente descritiva da carga parasitária do abomaso de caprinos jovens, assim como proporções simples entre os sexos.

\section{RESULTADOS E DISCUSSÃO}

Durante o estudo, os nematódeos encontrados parasitando abomaso foram Haemonchus contortus (Figura $1 \mathrm{~A}$ e 1B) e Trichostrongylus axei. Os caprinos abatidos foram observados no préabate, onde identificou-se principalmente anemia severa, além de pelos arrepiados e sem brilho. No pós abate foi observado além de fixação do parasito no órgão, edemas e lesões (Figura 1C) de mucosa abomasal e palidez da carcaça. 
FONSECA, Z.A.A.S. et al. Relação sexual do parasitismo por Haemonchus contortus em Caprinos (Capra hircus). PUBVET, Londrina, V. 5, N. 31, Ed. 178, Art. 1200, 2011.

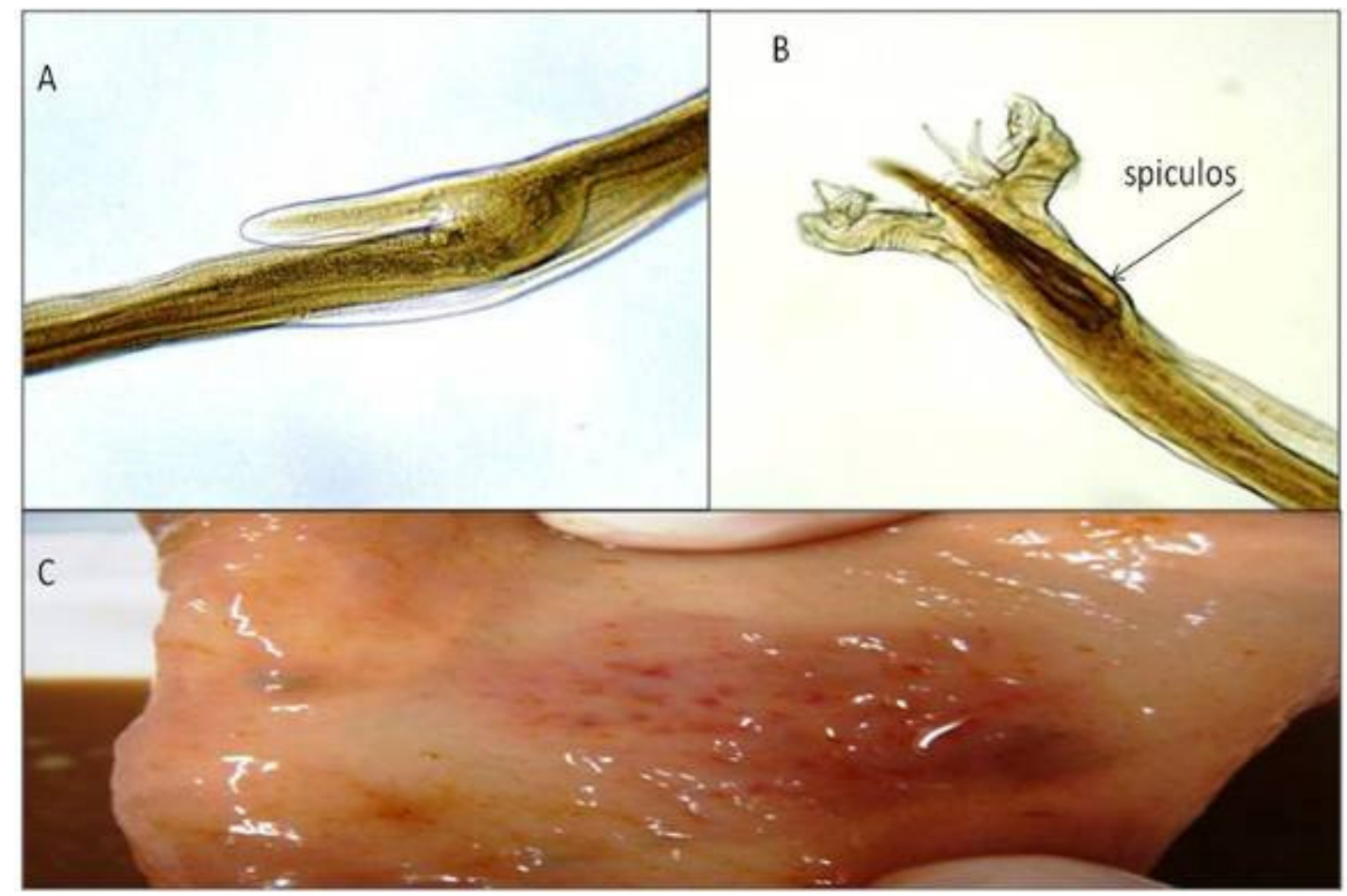

Figura 1. Características de identificação de $H$. contortus e suas lesões: A: Apêndice vulvar característico de fêmeas adultas. B: Bolsa copuladora com espículos evidentes característico dos machos. C: Edema e lesão provocada por $H$. contortus no Intestino delgado.

Segundo Dargie \& Allonby (1975), das espécies descritas acima, o H. contortus é a principal, pois além de elevada prevalência, apresenta grande patogenicidade. Os parasitas são hematófagos e a principal consequência do parasitismo é a anemia. A espécie $H$. contortus, parasita de pequenos ruminantes, é a espécie dominante em termos de intensidade de infecção, pois os animais infectados mostram-se altamente susceptíveis, com alta taxa de infecção e grande excreção de ovos pelos nematóides fêmeas, em comparação com outras espécies de ruminantes.

Em caprinos jovens, a população total observada de $H$. contortus recuperados durante o abate foram de 12282 exemplares, além de 178 espécimes de $T$. axei, sendo o número médio de Haemonchus sp 
FONSECA, Z.A.A.S. et al. Relação sexual do parasitismo por Haemonchus contortus em Caprinos (Capra hircus). PUBVET, Londrina, V. 5, N. 31, Ed. 178, Art. 1200, 2011.

encontrados no abomaso de 1.785 espécimes por animal. Concordando com Arosemena (1998), que descreveram o $H$. contortus e T. axei parasitando abomaso em coletas realizadas em abatedouros no sertão dos Inhamuns estado do Ceará. Ueno e Gonçalves (1998) descrevem o parasitismo abomasal por Haemochus e Trichostrongylus, sendo o $\mathrm{H}$. contortus a espécie de maior patogenia em comparação com o T. axei, desse modo uma população de 500 Haemonchus promove a mesma patogenia de uma população de 4.000 Trichostrongylus, necessitando de uma maior infrapopulação para o desenvolvimento da doença.

Estudos anteriores revelaram que mais de $80 \%$ da carga parasitária de caprinos é composta de $H$. contortus. Este parasita ocorre nas áreas de verão chuvoso, particularmente em regiões tropicais e subtropicais. Nos trópicos, em média $95 \%$ dos caprinos estão infectados, principalmente por Haemonchus spp. e Trichostrongylus spp. apresentando taxa de mortalidade acima de 40\% (GITHIGIA et al., 2001).

Do total de exemplares de $H$. contortus, 6.189 (50,4\%) eram machos e $6093(49,6 \%)$ eram fêmeas. Desse modo a relação macho e fêmea do parasito não foi estatisticamente significante, indicando que a carga parasitária se equilibra em ambos os sexos, sendo desse modo equivalentes. Demonstrando que embora as fêmeas sejam as principais responsáveis pela disseminação da espécie, sua população é semelhante a de machos encontrados, contribuindo ao se alimentar com o agravamento da hemoncose. Discordando com informações descritas por Ueno e Goçalves (1998), que descrevem ser a população de machos 70\% da carga parasitária composta por fêmeas, desse modo uma população total de 428 Haemonchus é composta de 240 fêmeas e 188 machos. 
FONSECA, Z.A.A.S. et al. Relação sexual do parasitismo por Haemonchus contortus em Caprinos (Capra hircus). PUBVET, Londrina, V. 5, N. 31, Ed. 178, Art. 1200, 2011.

\section{CONCLUSÕES}

Analisando o parasitismo por $H$. contortus e T. axei, pode-se observar que a carga parasitária de $H$. contortus foi bem superior ao encontrada por T. axei, demonstrando que as afecções decorrentes do parasitismo são agravadas pela espécie em evidência, podendo promover graves anemias e morte dos animais com elevada infecção parasitáia. Levando-se em consideração a espécie de maior frequência observou-se que as relações entre machos e fêmeas estão em equilíbrio, fato que facilita a copula e consequentemente a elevação da população de vida livre promovendo maior contaminação ambiental e parasitária.

Percebe-se ainda, que assim como na maioria dos rebanhos, a hemoncose aparece como o principal obstáculo a ser superado. O controle dessas infecções é essencial para um incremento de produtividade, e mais estudos epidemiológicos podem ser de grande valia para o alcance desse objetivo.

\section{BIBLIOGRAFIA}

AROSEMENA, N. A. E. Parasitismo por nematódeos gastrintestinais de ovinos e caprinos na região semi-árida dos Inhamuns. Fortaleza, 1998. 56 p, 1998. Dissertação de Mestrado, Universidade Estadual do Ceará.

CARVALHO, E.B., OLIVEIRA, M.A.G., DOMINHGUES, P.F. Base para criação de ovinos no estado de São Paulo. São Manuel: Associação Paulista de Criadores de Ovinos (ASPACO), 2.ed., p.81, 2001.

DARGIE, J. D.; ALLONBY, E. W. Pathophysiological of single and challenge infections of Haemonchus contortus in Merino sheep: studies on red cell kinetics and the 'self-cure' phenomenon. International Journal Parasitology, 5:147-157, 1975.

FREITAS, M. G. Helmintologia Veterinária. 6 ed. Belo Horizonte: Precisa, 1982. Apud : CAVAlCANTE, A. C. R.; VIEIRA, L. S.; CHAGAS, A. C. S.; MOLENTO, M. B. Doenças parasitárias de caprinos e ovinos epidemiologia e controle. Brasilia: Embrapa Informação Tecnológica, 2009. 
GITHIGIA, S. M. et al. Impacto of gastointestinal helminthes on production of the goats in Kenia. Small Ruminant Research, 42: 21-29, 2001.

PINHEIRO, A.C. Verminose Ovina. A Hora Vet., Porto Alegre, v.2, n.12, 1983.

QUADROS, D. G. et al. Prevalência de helmintos gastrintestinais em cabras e ovelhas pastejando capim maniçoba. In: REUNIÃO ANUAL DA SOCIEDADE BRASILEIRA DE ZOOTECNIA. FEALQ:SBZ. Anais... Campo Grande- MS, 2004.

SANTA ROSA, J. Enfermidade em Caprinos: diagnóstico, patogenia, terapêutica e controle. Brasília, DF: Embrapa-SPI; Sobral: Embrapa-CNPC, 1996. Apud: CAVALCANTE, A. C. R.; VIEIRA, L. S.; CHAGAS, A. C. S.; MOLENTO, M. B. Doenças parasitárias de caprinos e ovinos epidemiologia e controle. Brasilia: Embrapa Informação Tecnológica, 2009.

SANTOS, W. B.; AHID, S. M. M.; SUASSUNA, A. C. D. Aspectod epidemiológicos da caprinocultura e ovinocultura no município de Mossoró (RN). A Hora Veterinária, Porto Alegre, n.152, 2006. 